\title{
Shift Schedule Modification for Automated Manual Transmission Based on Road Slope Identification
}

\author{
H. Lu, X.F. Yin, X.H. Wu \\ Sichuan Provincial Key Laboratory of Automotive Engineering \\ Xihua University \\ Chengdu, China
}

\begin{abstract}
Identification of the road slope is a key issue for automated manual transmission (AMT) to have its shift schedule adapt to the slope change during operation. To tackle the problem of frequent gearshift on ramp of the traditional shift schedule, a slope recognition method based on the vehicle's acceleration is proposed and the traditional shift schedule has been modified using genetic algorithm. The shift performance of running on ramp has been analyzed and the traditional shift schedule has been modified to get rid of its weakness when traveling on the ramp. Genetic algorithm has been used to calculate the shift schedule. Simulation result show that modified shift schedule can adapt to the slope change effectively.
\end{abstract}

Keywords-slope recognition; shift schedule; automated manual transmission

\section{INTRODUCTION}

With the development of electronic and control technologies, automatic transmission has been widely used in modern vehicle. It reduces the fatigue strength of drivers and the requirements on the driver's driving skills, effectively improves the power performance, fuel economy, and emission of automobile. These properties are mainly affected by the shift schedule for the vehicle equipped with AMT (automated manual transmission), which defines the time of gear shifting according to the variation of the control parameters. The traditional shift schedule is based on vehicle speed and throttle opening on good level road, which does not consider the influence of slope on gearshift performance and therefore can not adapt to the slope change of road, and may make the gearshift occur frequently and also reduce the overall performance of the vehicle. In order to improve the adaptability of automatic transmission to the slope change of driving road, it is very important for AMT ( automated manual transmission) vehicle to modify the traditional shift schedule when the vehicle travels on ramp according to change of the slope of road.

\section{SLOPE RECOGNITION}

Slope could be recognized through the calculation of the difference between the theoretical acceleration corresponding to level road and the actual vehicle acceleration corresponding to real road, under the circumstance with same load [1]. Fig. 1 shows the flow chart of road slope identification, slope angle can be divided into different groups: level 4 degree, level 8 degree and level 12 degree. the road slope $\theta$ belonged to which groups can be found in Table 1 based on $\Delta$ a that is the difference of acceleration between theoretical and actual values [2]. Theoretical acceleration of the vehicle is obtained from the vehicle driving force equation, specific formula see $[3,4]$, we can get the actual acceleration by instantaneous vehicle speed differential.

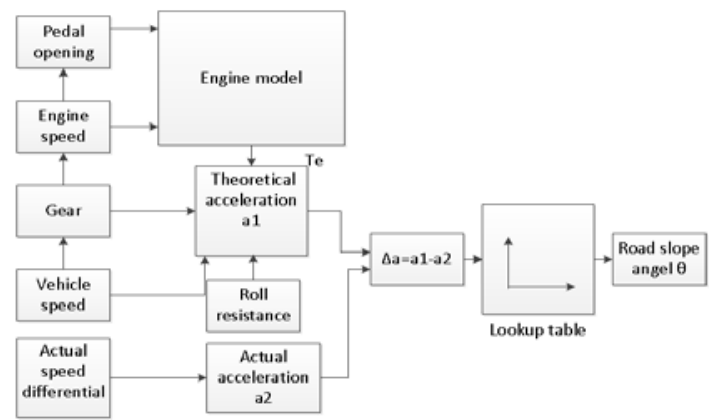

FIGURE I. FLOW CHART OF ROAD SLOPE IDENTIFICATION.

TABLE I. SLOPE GROUPS.

\begin{tabular}{|c|c|c|c|}
\hline \multirow{2}{*}{ Prameter } & \multicolumn{3}{|c|}{ Slope Angle } \\
\cline { 2 - 4 } & $4^{\circ}$ & $8^{\circ}$ & $12^{\circ}$ \\
\hline \multirow{2}{*}{$\Delta a\left(\mathrm{~m} / \mathrm{s}^{2}\right)$} & $<0.7275$ & $\begin{array}{c}0.7275 \sim 1.161 \\
8\end{array}$ & $1.1618 \sim 1.7356$ \\
\hline
\end{tabular}

III. SHIFT SCHEDULE ON RAMP

\section{A. Optimization Algorithm}

In the implementation of gearshift strategy, the road slope could be taken into account to optimize the shift schedule. And it should be able to meet the dynamic performance and fuel economy requirements of automobile, and can adapt to travel on the ramp. Therefore shift schedule making is a multiobjective optimization problem.

1) The optimization problem description: In this paper the throttle opening and velocity are used as shifting control parameters. The shift point selection only depends on velocity when the throttle opening is determined. Therefore the velocity is chosen as the decision variable to solve the shift points under different throttle opening.

To solve the multi-objective optimization problem, the sub-objective functions has been established at first, and then a comprehensive evaluation function has been built based the sub-objective functions.

a) Sub-objective function for dynamic performance : This article uses the absolute value of the acceleration difference 
between two adjacent gears under same throttle opening as the sub-objective function for dynamic performance.

$$
f_{\mathrm{d}}\left(u_{\mathrm{a}}\right)=\left|\frac{d u_{\mathrm{a} i}}{d t}-\frac{d u_{\mathrm{a}(i+1)}}{d t}\right|
$$

Here, $i$ is gear position, $u_{a}$ is the vehicle speed, $d u_{a} / d t$ is acceleration $\left\langle m / s^{2}>; f_{\mathrm{d}}\left(u_{\mathrm{a}}\right)\right.$ is the sub-objective corresponding to dynamic performance. If gearshift occurs at the point that makes the value of this function to be zero, the automobile will achieve its best dynamic performance.

b) 3.1.1.2 Sub-objective function for fuel economy: Fuel consumption rate be has been chosen as evaluation index for the fuel economy which can be expressed by

$$
b_{\mathrm{e}}=Q_{\mathrm{h}} / P_{\mathrm{e}}
$$

Here, $Q_{h}$ is the engine fuel consumption; be is the fuel consumption rate; $\mathrm{Pe}$ is the engine power which can be described as

$$
P_{e}=\frac{T_{e} n_{e}}{9550}
$$

Here, Te is the engine output torque, ne is the engine speed.

Similarly, the sub-objective function for fuel economy can be expressed as

$$
f_{f c}\left(u_{a}\right)=\left|b_{e i}-b_{e(i+1)}\right|
$$

$f_{\mathrm{fc}}\left(u_{\mathrm{a}}\right)$ is the sub-objective corresponding to fuel economy. If gearshift occurs at the point that makes the value of this function to be zero, the automobile will achieve its best fuel economy

c) Comprehensive evaluation function: In order to make compromise between the dynamic performance and fuel economy, linear weighting method has been used to construct the comprehensive evaluation function as follows Comprehensive evaluation function

$$
\left\{\begin{array}{l}
f\left(u_{\mathrm{a}}\right)=w_{\mathrm{d}} f_{\mathrm{d}}^{\prime}\left(u_{\mathrm{a}}\right)+w_{\mathrm{fc}} f_{\mathrm{fc}}^{\prime}\left(u_{\mathrm{a}}\right) \\
w_{\mathrm{d}}+w_{\mathrm{fc}}=1
\end{array}\right.
$$

Here, $w_{\mathrm{d}}$ and $w_{\mathrm{fc}}$ are the weight coefficients for dynamic performance and fuel economy respectively; $f_{\mathrm{d}}^{\prime}\left(u_{\mathrm{a}}\right)$ and $f_{\mathrm{fc}}^{\prime}\left(u_{\mathrm{a}}\right)$ are the normalized sub-objective functions for dynamic performance, and fuel economic respectively.

d) Constraint conditions: The first constraint condition should be satisfied is that the vehicle will not slow down immediately after upshift, i.e, the acceleration at the upshift point should meet the following equation

$$
g_{1}\left(u_{a}\right)=\frac{d u_{a}}{d t} \geq 0
$$

Here,g1 is the acceleration at the upshift point.

The engine speed should also be in the range of the minimum stable speed and the maximum speed corresponding to a certain throttle opening, which can be expressed as

$$
n_{e \min } \leq g_{2}\left(u_{a}\right)=\frac{i_{g} i_{0}}{0.377 r} u_{a} \leq n_{e \max }
$$

Here, $i g$ is the gear ratio of the $i^{\text {th }}$ gear; $i_{0}$ is the gear ratio of main reducer; $r$ is the wheel rolling radius; $n_{\text {emin }}$ is the minimum engine speed, $n_{\text {emax }}$ is the maximum engine speed. $g_{2}$ is the shift engine speed.

Regarding driving on ramp, the driving force should be able to overcome the driving resistance that takes into account the rolling resistance, air resistance and ramp resistance. the following equation should apply

$$
g_{3}\left(u_{a}\right)=F_{t}-F_{i}-F_{f}-F_{w} \geq 0
$$

Here, $g_{3}$ is the difference of force between diving force and driving resistance; $F_{f}, F_{w}, F_{i}$ are the road rolling resistance, the air resistance, the ramp resistance respectively[5].

To sum up, regarding the shift schedule on ramp, the following constraint conditions should be satisfied

$$
\begin{array}{ll}
\min & f\left(u_{\mathrm{a}}\right), \\
\text { s.t. } & g_{1}\left(u_{\mathrm{a}}\right) \geq 0, \\
& n_{\text {emin }} \leq g_{2}\left(u_{\mathrm{a}}\right) \leq n_{\text {emax }}, \\
& g_{3}\left(u_{\mathrm{a}}\right) \geq 0 .
\end{array}
$$

2) Shift schedule optimization: The shift schedule optimization calculation program has been developed using MATLAB language and its built-in global optimization toolbox which provides genetic algorithm (GA) to support optimization function. Relevant parameters with respect to genetic algorithm are set as follows: the population size is 20; the maximum number of generation for genetic algorithm is 100: crossover probability is 0.8 ; the rate of variation is 0.2. The main program flow is shown as Fig.2. Vehicle parameters are listed in Table 2.

TABLE II. THE VEHICLE PARAMETERS

\begin{tabular}{|c|c|c|c|}
\hline $\begin{array}{c}\text { Curb weight } \\
{[\mathrm{kg}]}\end{array}$ & 896 & $\begin{array}{c}\text { Wheel } \\
\text { radius [m] }\end{array}$ & 0.24 \\
\hline $\begin{array}{c}\text { Air resistance } \\
\text { coefficient }\end{array}$ & 0.34 & $\begin{array}{c}\text { Rolling } \\
\text { resistance } \\
\text { coefficient }\end{array}$ & 0.00116 \\
\hline $\begin{array}{c}\text { Transmission } \\
\text { efficiency }\end{array}$ & 0.96 & $\begin{array}{c}\text { Frontal area } \\
{\left[\mathrm{m}^{2}\right]}\end{array}$ & 1.937 \\
\hline $\begin{array}{c}\text { Main reduction } \\
\text { ratio }\end{array}$ & 4.05 & $1^{\text {st }}$ gear ratio & 3.41 \\
\hline $2^{\text {nd }}$ gear ratio & 1.895 & $3^{\text {rd }}$ gear ratio & 1.28 \\
\hline $4^{\text {th }}$ gear ratio & 0.914 & $5^{\text {th }}$ gear ratio & 0.758 \\
\hline
\end{tabular}




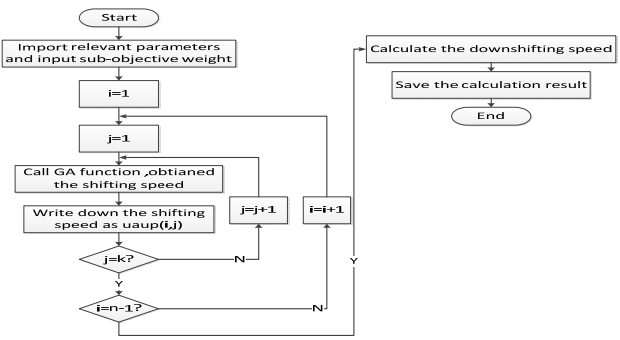

FIGURE II. FLOW CHART OF MAIN PROGRAM.

Two shift schedules have been calculated to represent two typical driving intentions, i.e., dynamic performance dominant or fuel economy dominant while driving on ramp.

With respect to the dynamic performance dominant shift schedule on ramp, the weights are set as: $w_{\mathrm{d}}=0.8, w_{\mathrm{fc}}=0.20$.

A dynamic performance dominant shift schedule on ramp under different slope can be calculated using the proposed optimization method. As an example the dynamic performance dominant shift curve under slope $8^{\circ}$ is shown as Fig.3.

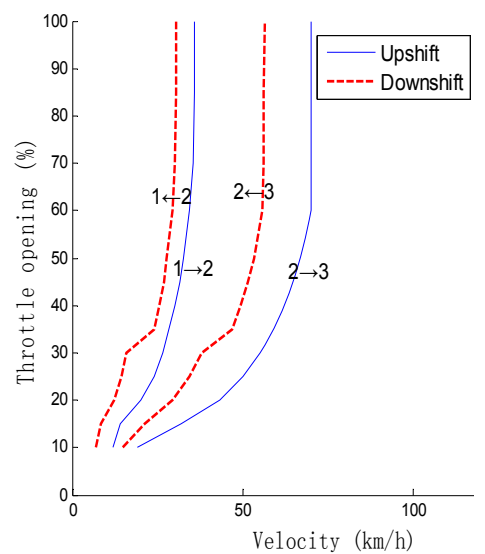

FIGURE III. MODIFIED DYNAMIC PERFORMANCE DOMINANT SHIFT SCHEDULE.

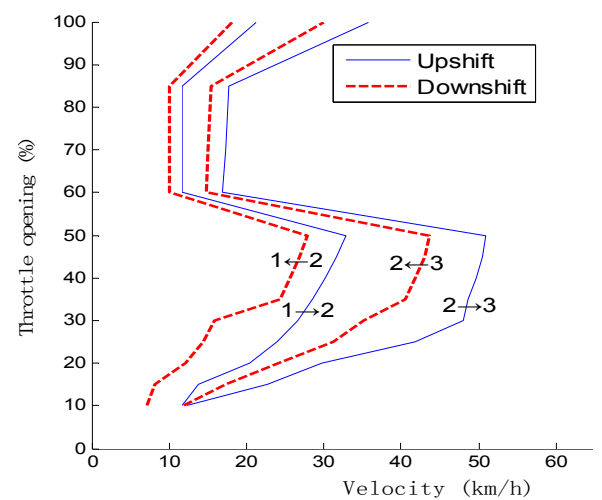

FIGURE IV. MODIFIED FUEL ECONOMY DOMINANT SHIFT SCHEDULE

Similarly, a fuel economy dominant shift schedule on ramp under different slope can be calculated with the weight combination of $w_{\mathrm{d}}=0.40$ and $w_{\mathrm{fc}}=0.60$. The fuel economy dominant shift curve under slope $8^{\circ}$ is shown as Fig.4.

As shown in Fig. 3 and Fig. 4, gearshift only occurs among the $1^{\text {st }}, 2^{\text {nd }}$ and $3^{\text {rd }}$ gears when the slope is $8^{\circ}$.

\section{SimUlation AND ANALysis}

To show the validity of the modification of shift schedule with consideration of slope, comparisons between the traditional and the modified shift schedules have been implemented through driving-on-ramp and a modified HWFET-MTN [6]cycle simulations.

\section{A. Driving-on-ramp simulation}

Fig. 5 and Fig. 6 show the simulation results of driving-onramp under constant accelerator pedal $20 \%$ and slope $8^{\circ}$, It's obvious that at the time $60 \mathrm{~s}$, the vehicle began to climb a ramp with the 4th gear, as the drive force is small than the resistance force, the velocity decreases sharply, and the gear is shifted from the 4th gear to the 3rd gear once the velocity meet that corresponding to downshift point. With respect to the traditional shift schedule, as the driving force in the 3rd gear is bigger than the driving resistance which does not consider the ramp resistance, the velocity rises and the gear is shifted from the 3 rd gear to the 4thgear again once the velocity meets that corresponding to the upshift point. And then, the vehicle drops into the cycle of downshift and upshift. On the contrary, the vehicle using the modified shift schedule under the same circumstance can hold the gear appropriately at the 3rd gear, which eliminates frequently gearshifts and improves driveability.

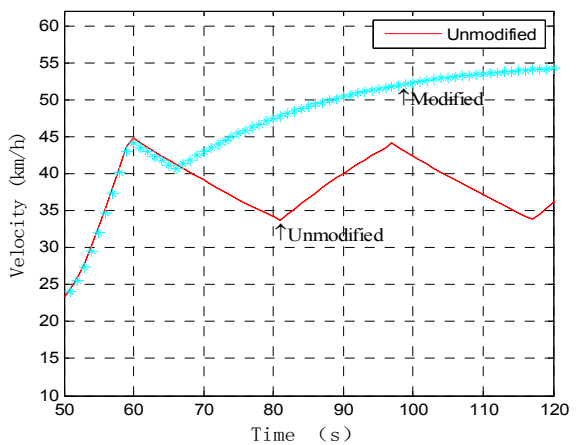

FIGURE V. COMPARISON OF SPEED ON SLOPE ROAD.

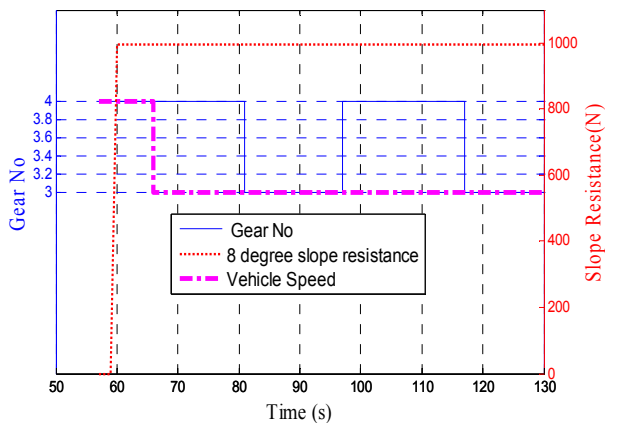

FIGURE VI. COMPARISON OF GEAR ON SLOPE ROAD. 


\section{B. Driving cycle simulation}

HWFET-MTN mainly aims at driving on highway. In this investigation the velocity profile of HWFET-MTN cycle has been modified through dividing the velocity by 1.6 to make the velocity close to the speed on the average road, as shown in the bottom of Fig. 7. The top sub-figure in Fig. 7 shows the ramp resistance under slope $8^{\circ}$, Fig. 8 illustrates different results of modified HWFET-MTN driving cycle simulation using the modified and traditional shift schedule. Obviously while vehicle travles on ramp using the traditional shift schedule, gearshift occurs frequently at the time $104 \mathrm{~s}, 106 \mathrm{~s}$, $108 \mathrm{~s}$, etc. and the number of gearshift is 13 . On the contrary, the vehicle using the modified schedule under the same circumstance can appropriately hold at the 3rd gear, and the number of gearshift is only 2 , which eliminates frequent gearshift and improves driveability, with only a slight decrease of fuel consumption compared to that using the traditional shift schedule.
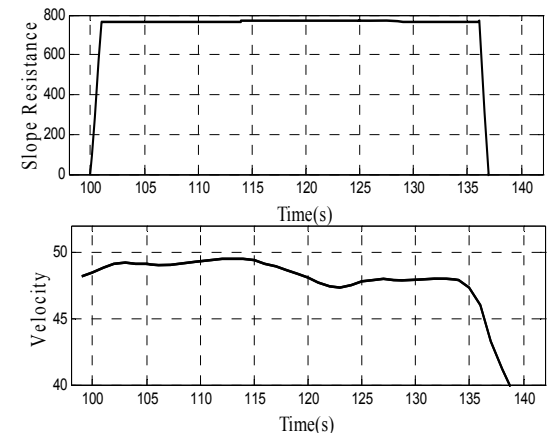

FIGURE VII. ROAD SLOPE AND TARGET SPEED

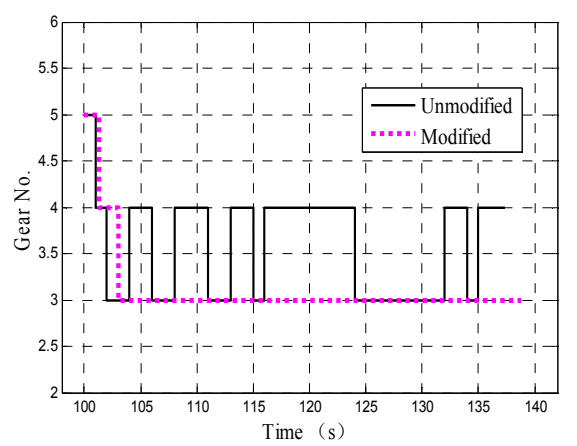

FIGURE VIII COMPARISON OF GEAR POSITION

\section{CONCLUSION}

To tackle the problem of frequent gearshift when AMT vehicle using traditional shift schedule travels on ramp, a modified shift schedule optimization method is put forward. Simulation results show that the optimized shift schedule could effectively reduce gearshift times and improve driveability on ramp.

\section{ACKNOWLEDGMENTS}

The work was supported in part by National Natural Science Foundation of China (Grant No. 51375402), Science \& Technology Department of Sichuan Province (Grant No. 2015TD0021), Sichuan Provincial Human Resources and
Social Security Department, and Innovation Fund for Graduate Students at Xihua University (Grant No. ycjj2014094).

\section{REFERENCES}

[1] Zhang, T., Ge, A., Liu, B., Guo, L., and Zhu, Y., Shift Schedule Based on Vehicle Loading, Transactions of the Chinese Society of Agricultural Machinery, 35(3), pp.9-12,2004.

[2] Jin, H., Li, L., and Li, B., Slope Recognition Method Based on Acceleration Interval Judgment, China Journal of Highway and Transport, 23(1),2010

[3] Ge, A., Theory and Design of Automatic Transmission, Mechanical Industry Publishing House, Beijing, China, pp.1-74,1993

[4] Jin, H., Ge, A., Qin, G., and Lei, Y., Study on Slope Recognition Method Based on Vehicle's Longitudinal Dynamics, Chinese Journal of Mechanical Engineering, 38(1), pp. 79-82, 86,2002,

[5] Li, L., Zhang, G., Song, J., and Huang, Q., Research on Automated Manual Transmission Shift Schedule based on Equivalent Slope, Joumal of Highway and Transportation Research and Develoment, 28(2), pp.146-147,2011.

[6] Zhang, F., Research on Driving Cycle of City Vehicles, Wuhan University of Technology: Wuhan, China, pp.13,2005. 